\title{
Persistence of Energy Savings of Lighting Retrofit Technologies at the Forrestal Building
}

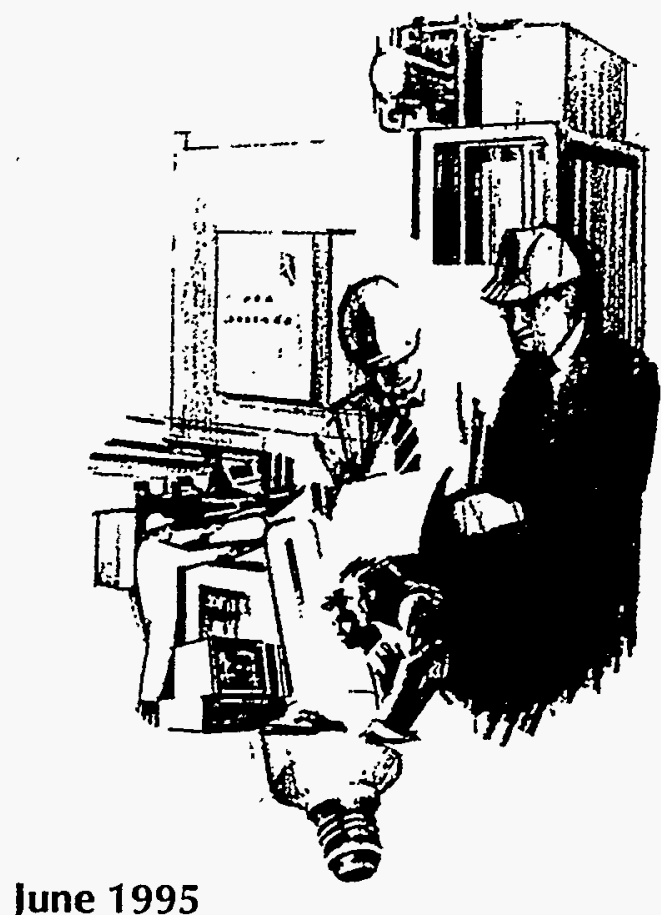

\section{RECEIVED}

AUG 091995

OSTI

Prepared for the U.S. Department of Energy Federal Energy Management Program under Contract DE-AC06-76RLO 1830

Pacific Northwest Laboratory

Operated for the U.S. Department of Energy by Battelle Memorial Institute

\section{*attelle}




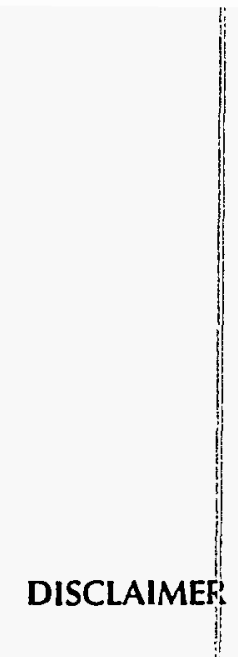

This report was prepared as an account of work sponsored by an agency of the United States Government. Neither the United States Government nor any agency thereof, nor Battelle Memorial institute, nor aryy of their employees, makes any warranty, express or implied, or assumes any legial liability or responsibility for the accuracy, completeness, or usefulness of any information, apparatus, product, or process disclosed, or represents that its use would not infringe privately owned rights. Reference herein to any specific commericial product, process, or service by trade name, trademark, manufacturer, or otherwise does not necessarily constitute or imply its endorsement, recommendation, or favoring by the United States Government or any agency thereof, or Battelle Memorial Institute. The views and opinions of authors expressed herein do not necessarily state or reflect those of the United States Government or any agency thereuf.

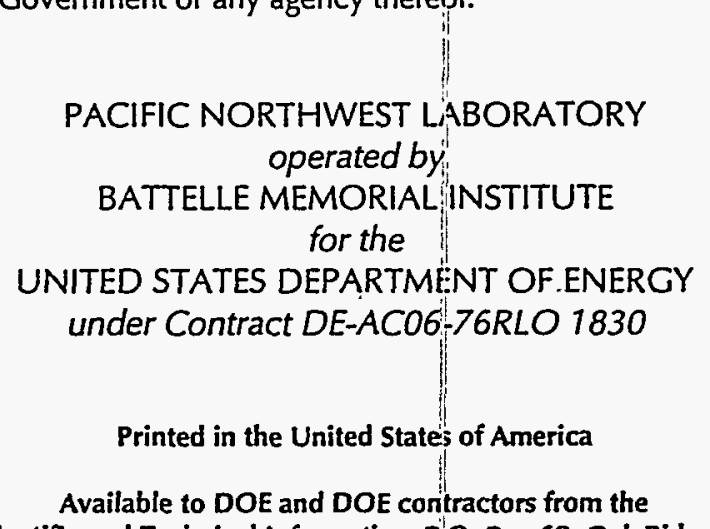

Office of Scientific and Technical Information, P.O. Box 62, Oak Ridge, TN 37831; prices available from (615) 576-8401.

Available to the public from the National Tiechnical Information Service, U.S. Department of Commerce, 5285 Port Royal Rd., Springfield, VA 22161 


\section{DISCLAIMER}

Portions of this document may be illegible in electronic image products. Images are produced from the best available original document. 
PNL-10543

UC-350

\section{Persistence of Energy Savings of Lighting Retrofit Technologies at the Forrestal Building}

W. D. Chvála, Jr.

R. R. Wahlstrom

M. A. Halverson

June 1995

Prepared for the Federal Energy Management Program

U.S. Department of Energy under Contract DE-AC06-76RLO 1830

Pacific Northwest Laboratory

Richland, Washington 99352 
$\begin{array}{llll} & \ldots & \ldots & \cdots\end{array}$ 


\section{Preface}

The goal of the U.S. Department of Energy (DOE) Federal Energy Management Program (FEMP) is to facilitate energy efficiency improvements at federal facilities. This is accomplished by a balanced program of technology development, facility assessment, and use of cost-sharing procurement mechanisms. Technology development focuses upon the tools, software, and procedures used to identify and evaluate energy efficiency technologies and improvements. For facility assessment, FEMP provides metering equipment and trained analysts to federal agencies exhibiting a commitment to improve energy use efficiency. To assist in procurement of energy efficiency measures, FEMP helps federal agencies devise and implement performance contracting and utility demand-side management strategies.

Pacific Northwest Laboratory ${ }^{(a)}$ supports the FEMP mission of energy systems modernization. Under this charter, the Laboratory and its contractors work with federal facility energy managers to assess and implement energy efficiency improvements at federal facilities nationwide.

This report documents the third and final phase of a field metering study at the DOE Forrestal building. The first two phases of the metering study quantified the energy savings of a major lighting retrofit. The third phase involved leaving two data loggers installed for an extended period of time to assess the persistence of energy savings over time.

(a) Pacific Northwest Laboratory is a multiprogram national laboratory operated for the U.S. Department of Energy under Contract DE-AC06-76RLO 1830 by Battelle Memorial Institute. 



\section{Summary}

In 1989, the Forrestal Building, headquarters for the U.S. Department of Energy, was chosen for a major lighting retrofit project. The project replaced the aging lighting system with newer, energy-efficient fixtures. Pacific Northwest Laboratory conducted a three-part monitoring study at the Forrestal Building to 1) characterize building energy use, 2) empirically measure savings realized by the lighting retrofit, and 3 ) determine the persistence of energy savings. This report summarizes the findings from the third and final monitoring phase.

Two data loggers were left installed at the Forrestal Building and data were collected for a 12-month period after the lighting retrofit was completed. An analysis-of-variance test indicated that the mean monthly lighting demand is increasing. A regression analysis performed on the data indicated that the mean monthly lighting demand for workdays is increasing at a rate of $0.3652 \pm 0.1101 \mathrm{~kW} / \mathrm{mo}$. The nonworkday demand is increasing at a rate of 0.3408 $\pm 0.1027 \mathrm{~kW} / \mathrm{mo}$. During the same period, workday mean monthly plug load demand increased $0.0912 \pm 0.0275 \mathrm{~kW} / \mathrm{mo}$., while nonworkday plug loads decreased slightly.

The gradual increase, though significant, is reduced when compared to the $56 \%$ savings recorded after the lighting retrofit. The increase is attributed to a combination of occupants returning to original (pre-retrofit poor) behavior and a small set of occupancy sensors being defeated by building occupants. Degradation of lighting fixtures from "burn-in time" was ruled out because all burn-in time is expected in the first few months and the increasing trend persists over the 11 months of this study.

Because the lighting demand was still increasing at the end of the study, without further data collection, it was not possible to determine when the increase would level out. Therefore, the true energy savings from the lighting retrofit remain unknown. 


\section{Acknowledgments}

The authors gratefully acknowledge the assistance of Louis Harris and Michael Schincovich, U.S. Department of Energy; and Richard Szydlowski, John Stoops, John Schmelzer, John Keller, and Andrea Currie, Pacific Northwest Laboratory, for their support in some of the early phases of this project and for ongoing support and consultation during the final phase. 



\section{Contents}

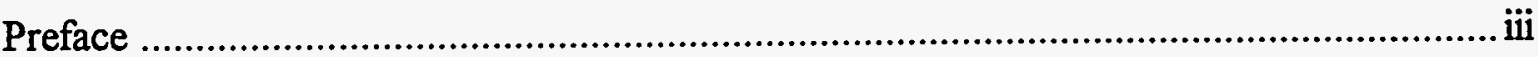

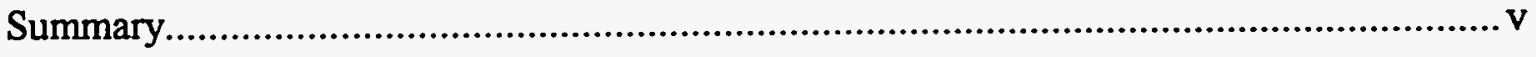

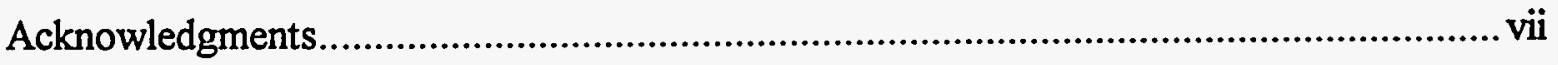

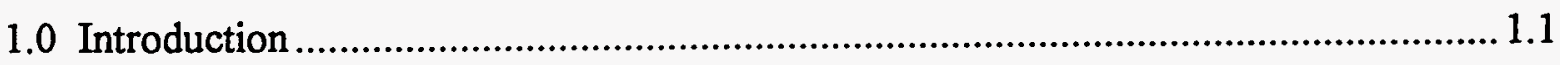

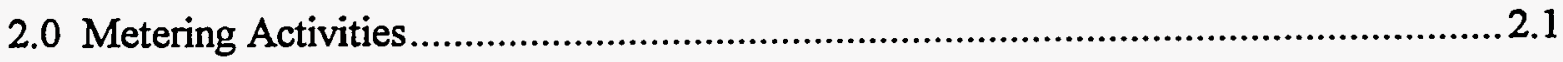

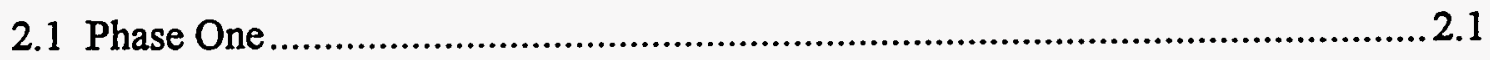

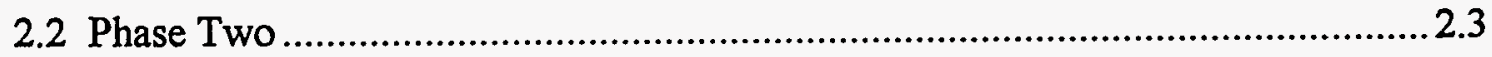

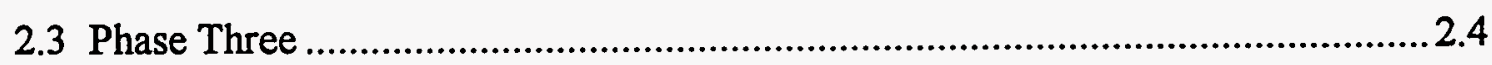

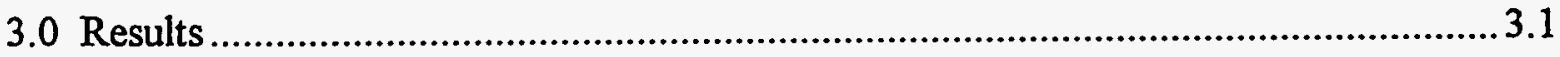

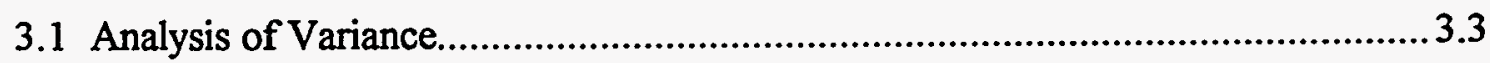

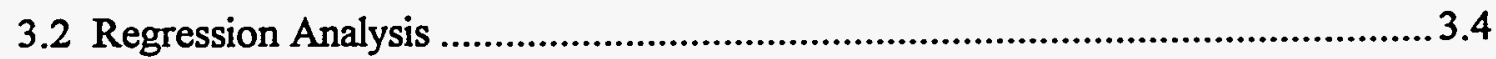

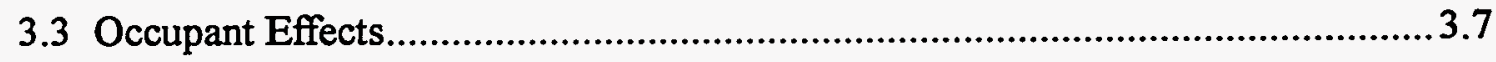

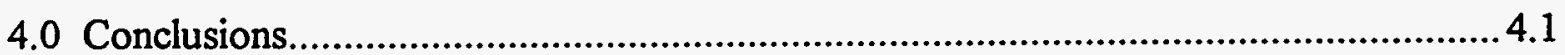

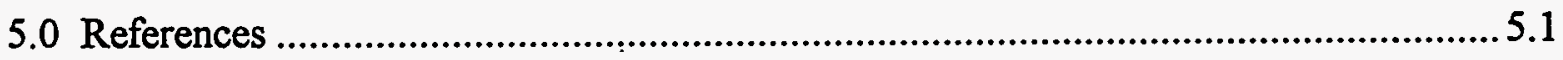

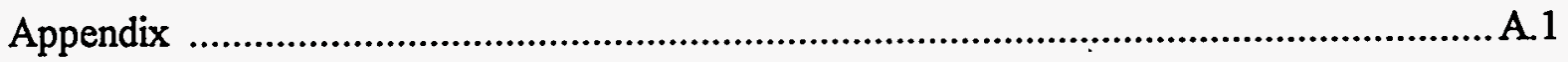




\section{Figures}

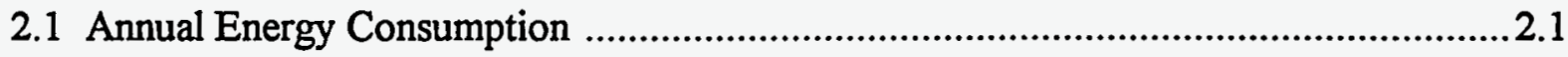

2.2 Workday Building-Demand Profile .....................................................................2.2

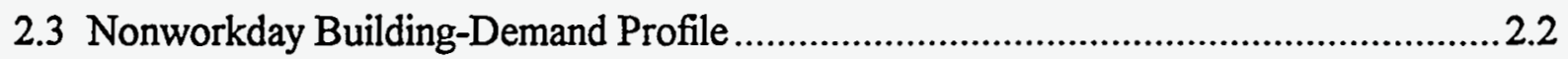

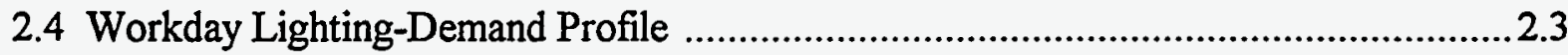

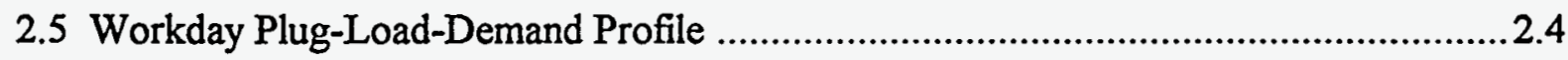

3.1 Lighting Daily Folds for Each Month During the Study .............................................. 3.1

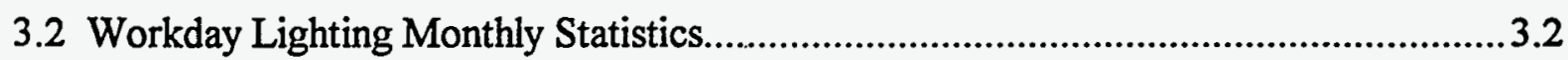

3.3 Nonworkday Lighting Monthly Statistics....................................................................3

3.4 Workday Average Lighting Demand Each Month .................................................... 3.5

3.5 Nonworkday Average Lighting Demand Each Month ................................................. 3.5

3.6 Workday Average Plug-Load Demand Each Month ...................................................

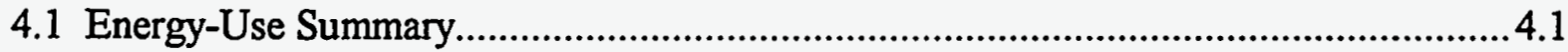

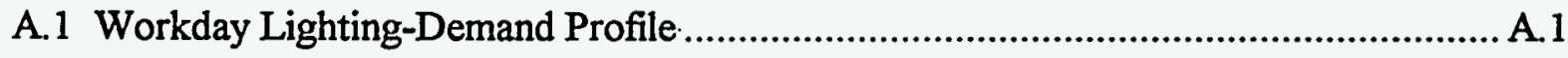

A.2 Nonworkday Lighting-Demand Profile . ............................................................

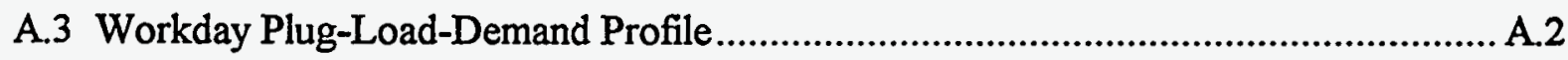

A.4 Nonworkday Plug-Load-Demand Profile ............................................................. A.2

A.5 Workday Plug-Load Monthly Statistics ................................................................... A.3

A.6 Nonworkday Plug-Load Monthly Statistics................................................................. A.3

A.7 Workday Average Plug-Load Demand Each Month.............................................. A.4

A.8 Nonworkday Average Plug-Load Demand Each Month ............................................4

\section{Tables}

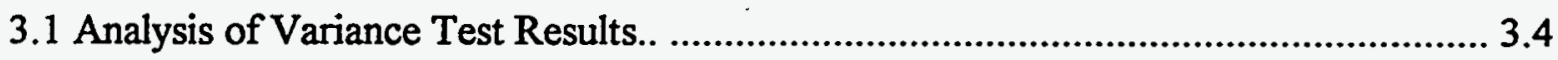

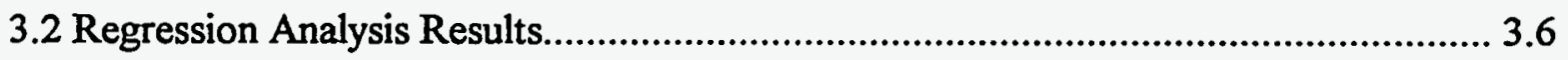




\subsection{Introduction}

The Forrestal Building in Washington, D.C. is the headquarters for the U.S. Department of Energy (DOE). In 1989, the Forrestal Building was chosen for a relighting project to replace its vintage (circa mid-1960) lighting fixtures with newer energy-saving fixtures and lights. The project was a shared energy savings project for the Federal Relighting Initiative operated by the Federal Energy Management Program at DOE.

The Forrestal Building is a 1.7-million-square-foot office building with 1.14 million square feet of occupiable assigned areas. The Forrestal Building is actually a complex of three buildings, commonly referred to as the North, West, and South (Cafeteria) Buildings. Heating and cooling are provided by a General Services Administration central distribution system that serves a number of buildings in the heart of Washington, D.C. Because of the presence of district heating and cooling, the electrical profiles for the Forrestal Building show the classic "hat-shaped" load profiles often associated with lighting and plug loads. This simplified the task of conducting a metering study because seasonal heating and cooling requirements can be easily separated from the building's electrical system.

Because of its importance as an example of potential energy savings for other DOE facilities, Pacific Northwest Laboratory (PNL) was contracted to assess the building energy use prior to and after the lighting retrofit. Accurately demonstrating the energy savings was critical to the success of the project. The PNL monitoring activities consisted of three distinct phases: preretrofit, short-term monitoring; post-retrofit, short-term monitoring; and post-retrofit, long-term monitoring.

This report gives the metering activities performed for this final phase of the monitoring study (Section 2.0), the results of the study (Section 3.0), the conclusions drawn from the data input (Section 4.0), the references cited herein (Section 5.0), and an appendix containing additional energy plots. 


\subsection{Metering Activities}

The project's objectives required PNL to perform three metering activities in conjunction with the lighting retrofit. The goal of Phase One was to assess the total building electrical end uses before the lighting retrofit and develop a demand profile descriptive of the Forrestal Building. Phase Two was concerned only with total building lighting and plug load electric demand after the lighting retrofit. Comparison of the Phase Two building lighting and plug load to the lighting and plug load component of Phase One demonstrates the energy saved by the retrofit. Phase Three looked at the persistence of energy savings by leaving several loggers installed long term to detect any increase in energy use with time.

\subsection{Phase One}

The first phase was an extensive end-use metering study conducted in 1990. This study established "baseline" electric usage at the Forrestal Building and disaggregation of that usage into components. The baseline study separated building electric use into lighting; plug loads (office equipment); heating, ventilation, and air conditioning (HVAC); motor control center; elevators; main-frame computers; and other loads (cafeteria, telephone system, etc.).

The pie chart in Figure 2.1 shows the annual electric consumption for the Forrestal Building in May 1990 before the lighting retrofit. Lighting consumed $33 \%$ of the building total electricity, followed by HVAC system at $25 \%$, and plug loads at $11 \%$ of the building total.

Throughout this report, the term, workday, refers to a day during the standard workweek, Monday through Friday. The term, nonworkday, refers to weekends and holidays.

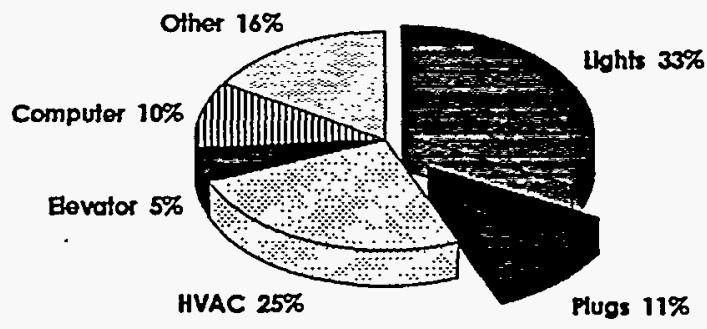

Figure 2.1. Annual Energy Consumption

Figure 2.2 shows a typical workday profile (based on 15-min metered end-use data collected during the baseline work). The average total building electric demand during peak hours is approximately $5200 \mathrm{~kW}$. The average building electric demand during off-peak hours is $2100 \mathrm{~kW}$. 


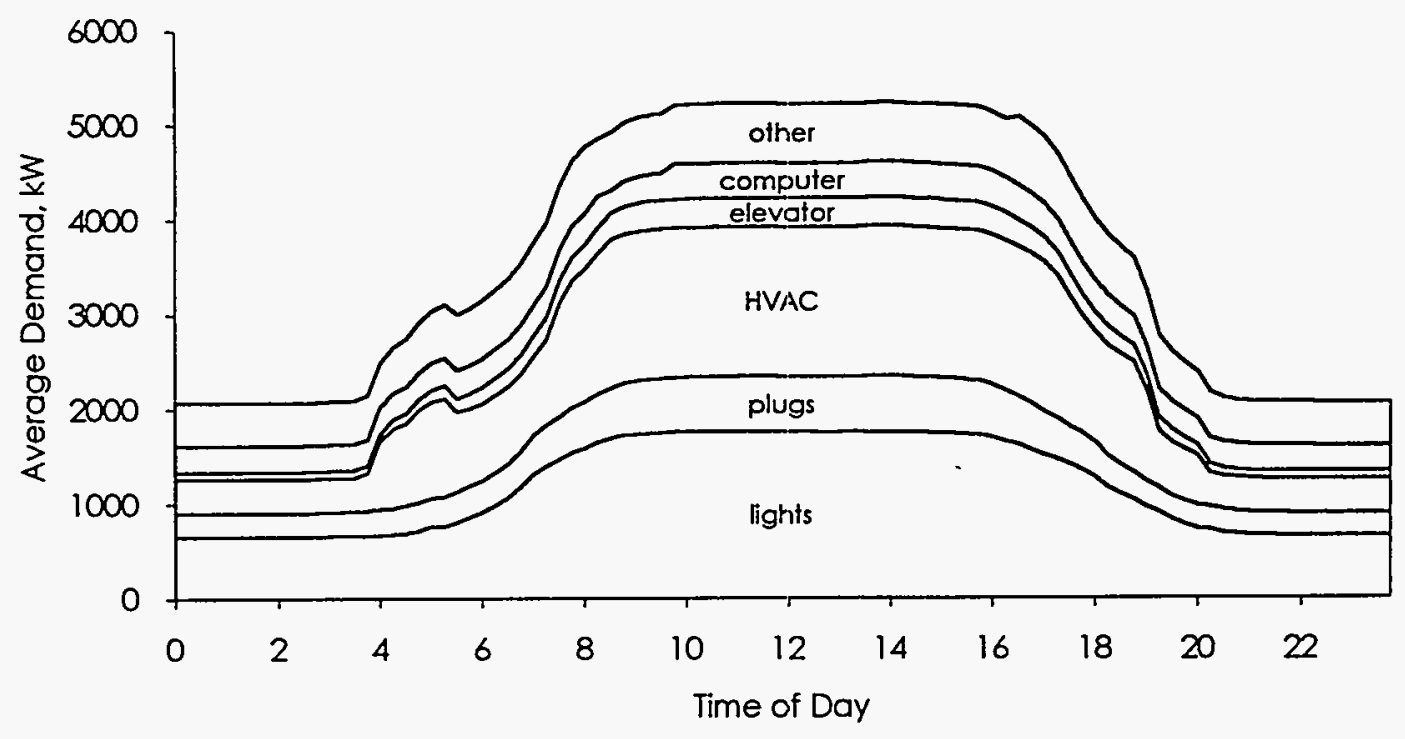

Figure 2.2. Workday Building-Demand Profile

Figure 2.3 shows a typical nonworkday building-demand profile. The average total building electric demand is approximately $2100 \mathrm{~kW}$. The results of the baseline work are presented in detail in Stoops et al. (1990) and Mazzucchi (1992).

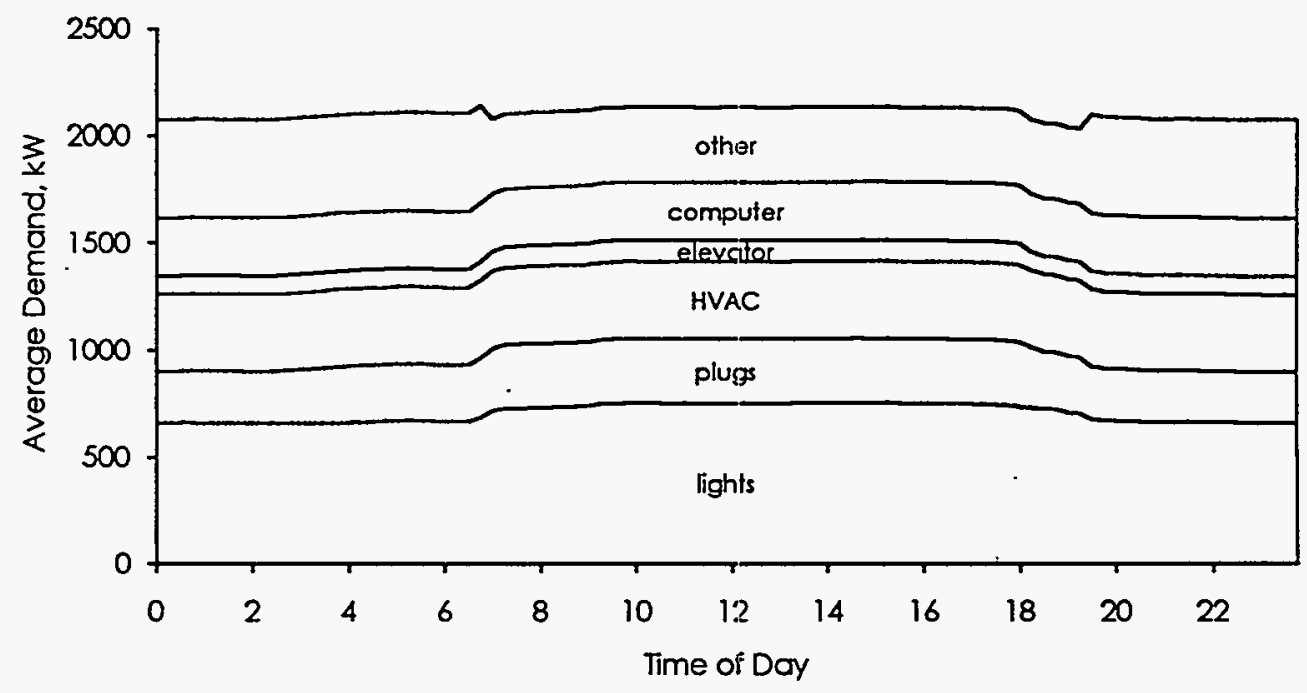

Figure 2.3. Nonworkday Building-Demand Profile 


\subsection{Phase Two}

The second end-use metering activity occurred in late 1993, after the lighting retrofit had been completed. A second PNL team conducted a metering study paralleling the lighting and plug-load component of the earlier study. The study consisted of short-term monitoring (i.e., approximately 1 week) at 50 electrical panels and one-time measurements at the rest of the 131 electrical panels providing power to lighting fixtures and receptacle outlets throughout the building. All data collection took place during October and November 1993.

By duplicating the previous study as closely as possible, the amount of savings from the lighting retrofit could be determined. It was found that electric lighting consumption was reduced by $56 \%$ on an annual basis ( $55.4 \%$ workday and $57.4 \%$ nonworkday). The peak electric demand was reduced $53.5 \%$ during the workday and $49.6 \%$ during the nonworkday. Figure 2.4 shows the decrease in the workday lighting-demand profile. Figure 2.5 shows the decrease in the nonworkday lighting-demand profile. The nonworkday profile experienced a similar decrease (see Appendix).

The post-retrofit metering produced one unexpected result - the plug loads increased $13.3 \%$ from 1990 to 1993 . Although this result is affirmed by current national trends, such a dramatic result was unexpected. A $13.3 \%$ increase over 42 months amounts to an annual increase of $3.8 \%$. Figure 2.5 shows the increase in building plug-load-demand profile. The nonworkday profile experienced a similar increase (see Appendix).

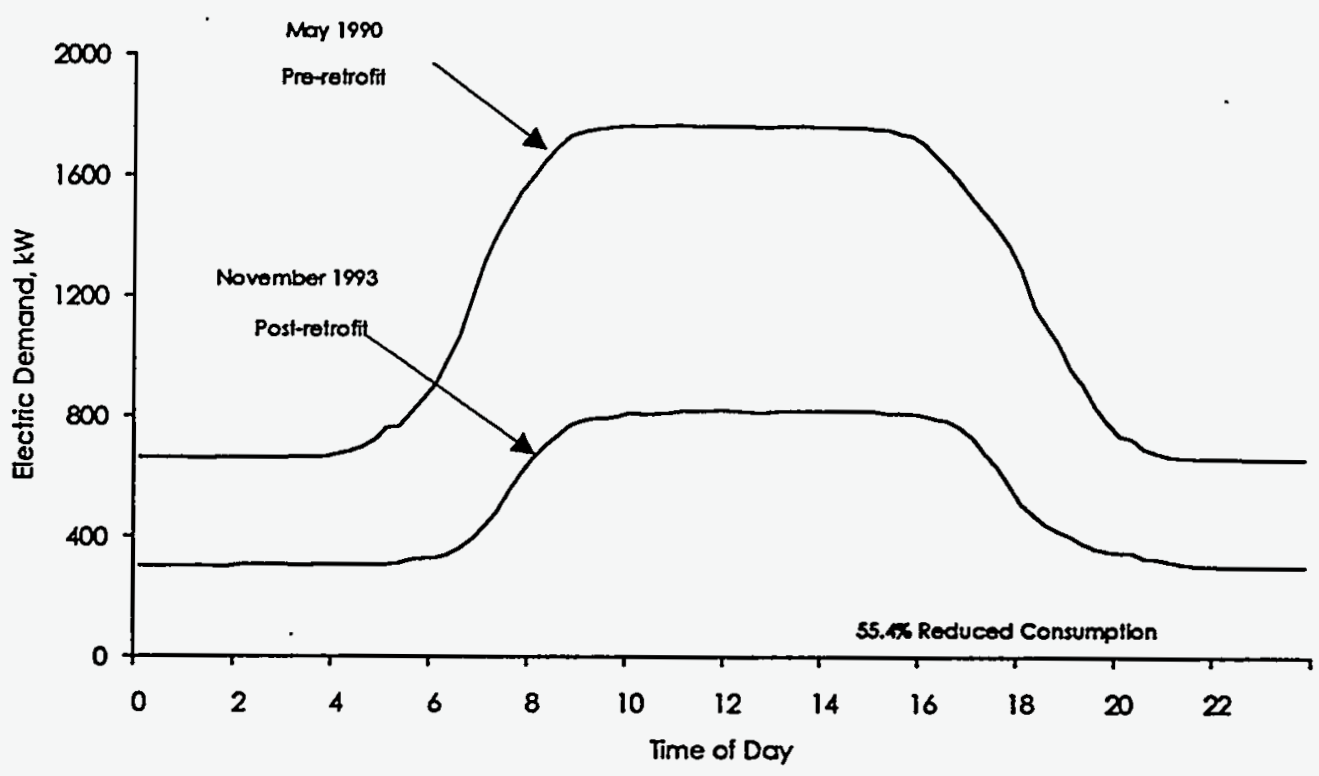

Figure 2.4. Workday Lighting-Demand Profile 


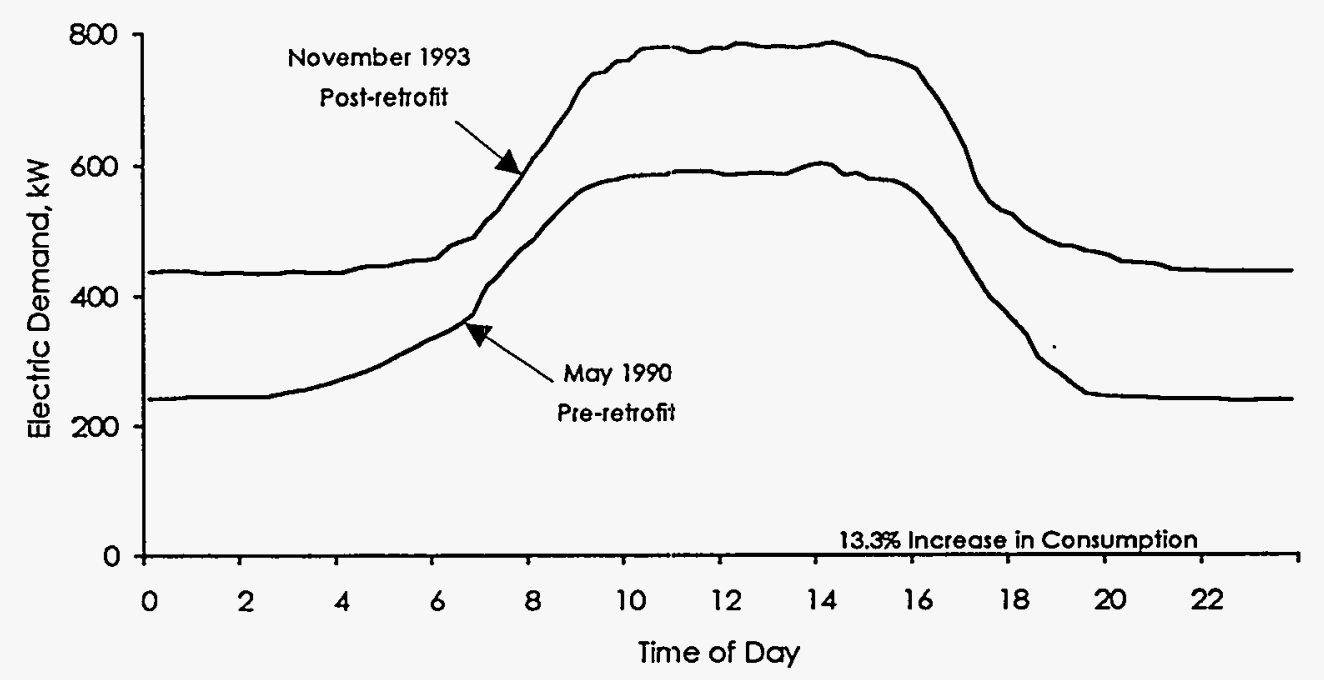

Figure 2.5. Workday Plug-Load-Demand Profile

Detailed results and explanations of the study methodology from the post-retrofit metering activities are presented in detail in Halverson et al. (1994).

\subsection{Phase Three}

The final metering study involved leaving two Synergistics C180e data loggers from the post-retrofit metering activity installed for an extended period of time. The two data loggers were left installed in electrical rooms 5E-053 and 4B-133. Each room contains panels servicing lights and plugs. The data loggers captured lighting and plug loads for a portion of the floor they were located on, in addition to an identical portion of the floor above and below. Six panels were monitored by each data logger.

The two data loggers collected hourly data that were down loaded periodically to PNL via telephone lines. All phase-independent data were summed to produce panel totals for both lights and plugs. Data were collected from November 3, 1993 to September 30, 1994.

Although budgets prohibited conducting a full-scale, long-term monitoring study, it was felt that two data loggers left installed would be able to accurately assess the long-term persistence of energy savings from the lighting retrofit in the Forrestal Building. Because the issue at hand is persistence of energy savings, persistence in two major zones of the building will indicate if the lighting retrofit is having the desired effect. 


\subsection{Results}

The first task was to plot the results to see if any visual increase in energy use could be seen. Figure 3.1 shows the workday lighting-demand profile for each month and the average of all the demand profiles for each day during a month. The monthly lighting profiles show the hatshaped demand nature typical for the Forrestal Building, but also seems to indicate a slight increase in lighting loads each month.

The z-axis in Figure 3.1 is the electric demand in kilowatts for the six panels metered in our sample. Demand values should not be confused with total building demand, which was reported in the first two phases of the study.

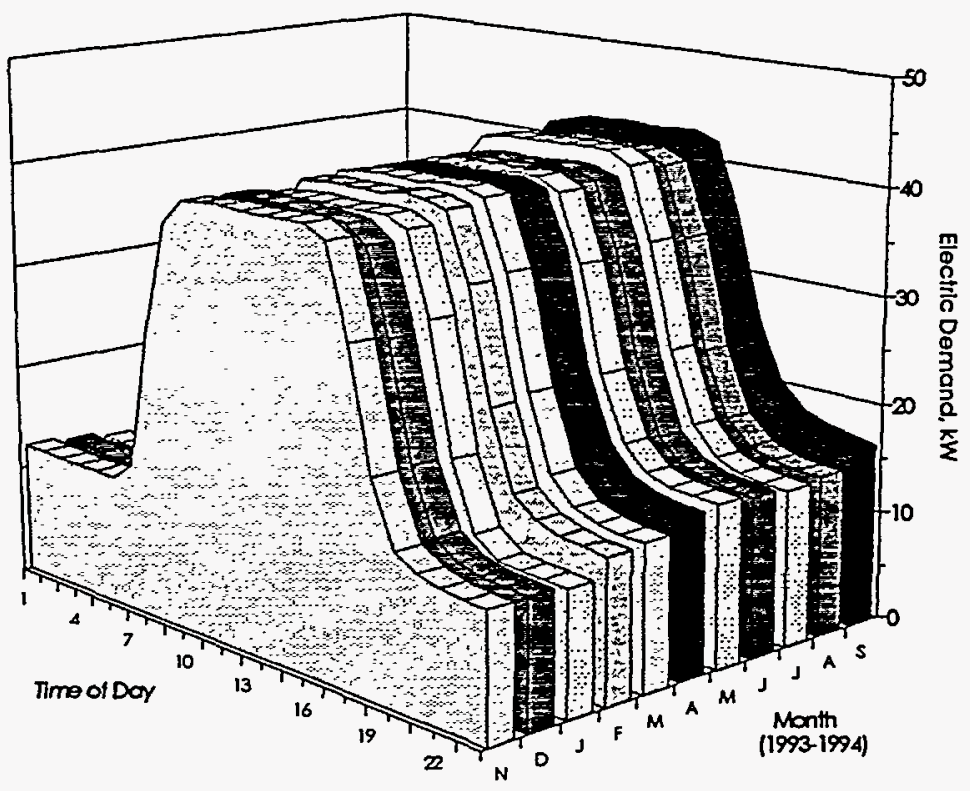

Figure 3.1. Lighting Daily Folds for Each Month During the Study

Next the data were analyzed using data access software developed by PNL. This software processes the data into various forms - raw data, daily folds (24-hour averages), monthly profiles, etc. Daily statistics - maximum, minimum, and average demand - were calculated for the sum of all the panels monitored. The daily statistics were combined into monthly statistics as follows:

- The average demand is the average of all the demand values for each day. By multiplying the average demand times the number of hours in a day, the daily consumption can be obtained. 
- The average of maximums is the average value of the maximum value for each day during a month.

- The moximum of maximums is the single highest demand value during the month.

- The average of minimums is the average value of the minimum value for each day during a month.

- The minimum of minimums is the single lowest demand value during the month.

As before, days were grouped into two types: workdays and nonworkdays. Problems arose in dealing with off-normal days that did not fit clearly into either category. A harsh winter in Washington, D.C. caused people to miss days of work; consequently, weekends were worked to make up for lost time. Also, as in other metropolitan areas, extra vacation days were used to make 3-day weekends into a 4-day vacation. Because the profiles are intended to describe typical workdays and nonworkdays, all off-normal days were removed from the analysis. Plug loads were used as a better indicator of off-normal occupancy than lighting loads.

Figure 3.2 shows the workday lighting monthly statistics, the monthly average of all the daily statistics. All five indicators experienced a slightly upward trend. The same result was found in the nonworkday monthly statistics shown in Figure 3.3.

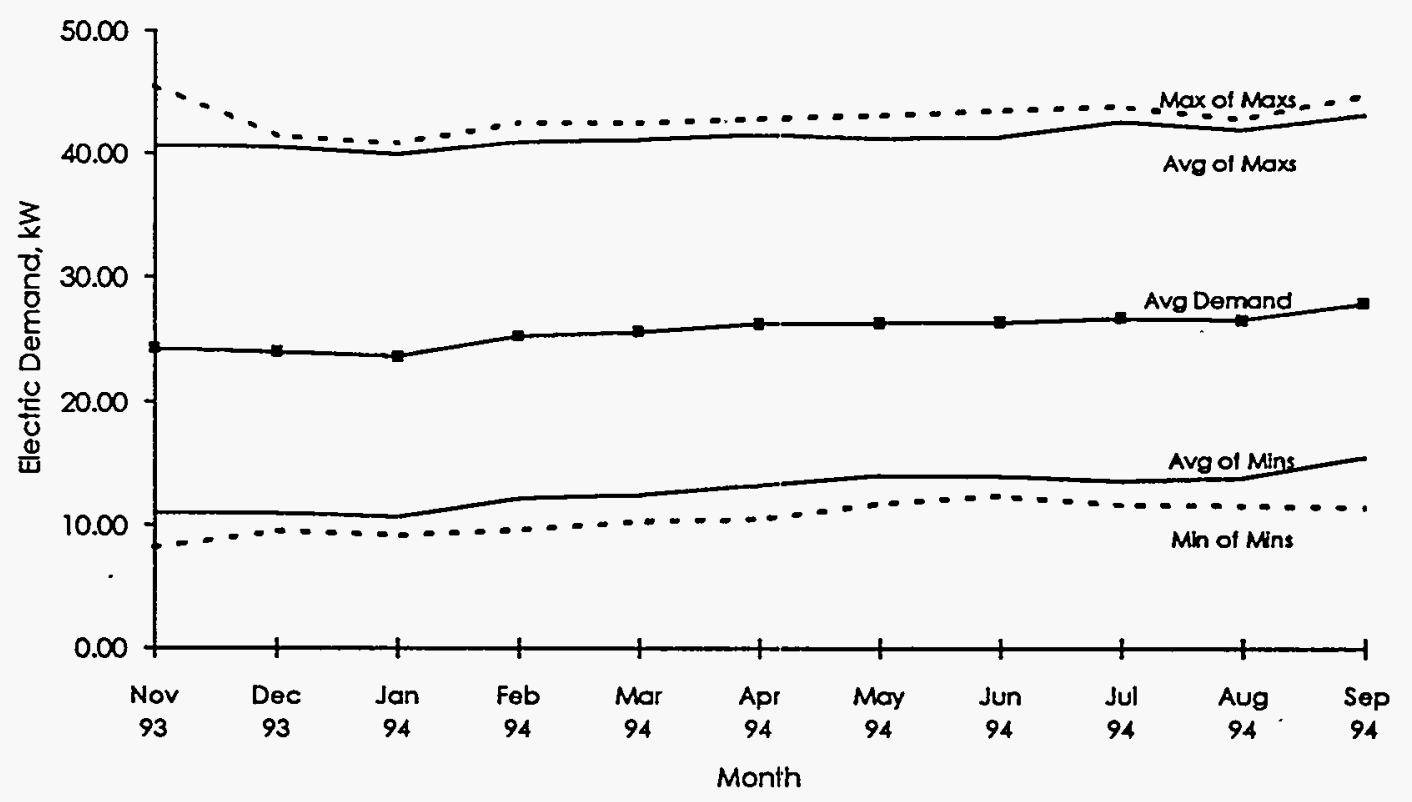

Figure 3.2. Workday Lighting Monthly Statistics 


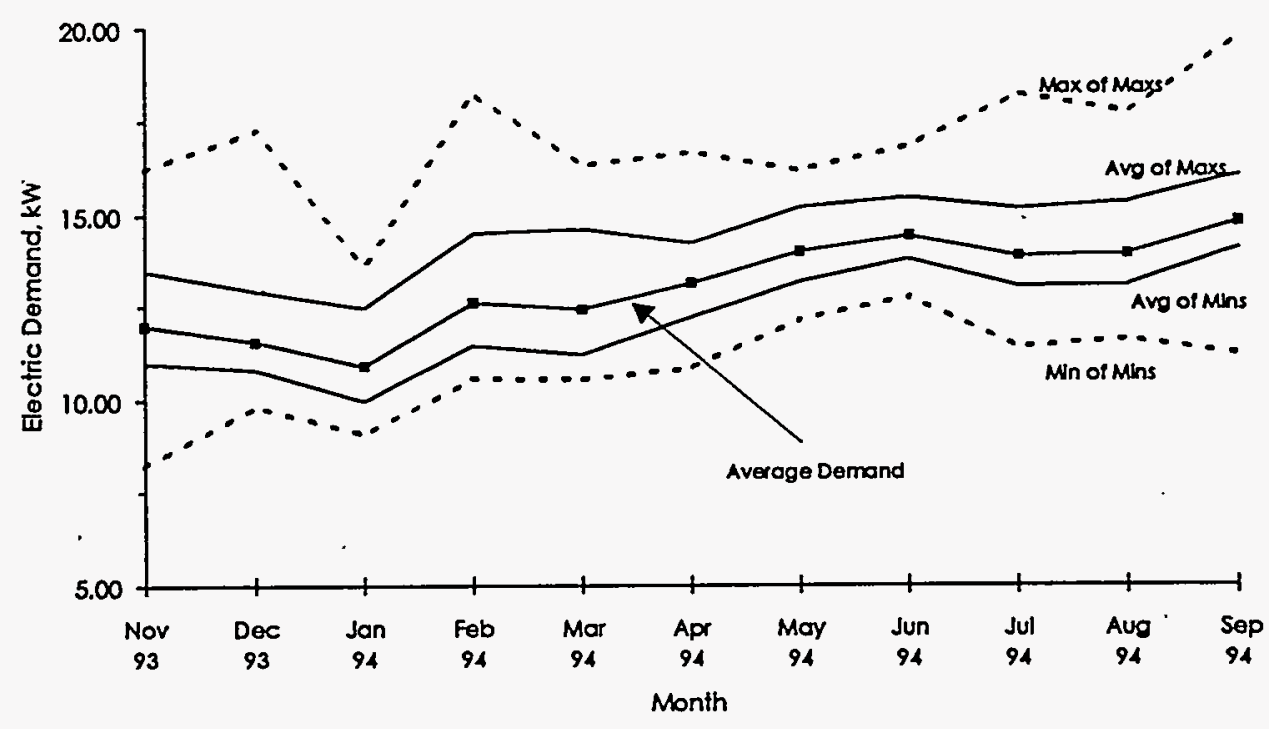

Figure 3.3. Nonworkday Lighting Monthly Statistics

The dip in lighting loads in January is counterintuitive because January has the shortest days. However, large buildings with a small perimeter-to-interior space ratio like the Forrestal Building are less affected by day-lighting factors. The harsh weather may have had some influence in people working shorter days or not working at all.

\subsection{Analysis of Variance}

The first statistical test performed was an analysis-of-variance (ANOVA) test, which allows us to determine if the lighting loads are increasing by comparing the mean energy use each month. The ANOVA test is used to determine if there is a statistically significant increase in the mean $(\mu)$ energy use between months, taking into account the distribution of the mean daily values.

The ANOVA analysis tests the null hypothesis: $\mathrm{H}_{0}: \mu_{\mathrm{NOV}}=\mu_{\mathrm{DEC}}=\mu_{\mathrm{JAN}}=\ldots=\mu_{\mathrm{SEP}}$. If the ANOVA test produces a large $P$ value, there is insufficient evidence to reject the null hypothesis, $\mathrm{H}_{0}$; therefore, assuming it is true. A large $\mathrm{F}$ statistic indicates accepting the alternative that the means are not equal.

An ANOVA test was performed on each set of monthly data for workday lights, workday plug loads, nonworkday lights, and nonworkday plug loads. In each case, the $P$ value was zero (i.e., <0.000) and the F statistic was large, indicating that the mean values for each month are not statistically equal (Table 3.1 ). 
Table 3.1. Analysis-of-Variance (ANOVA) Test Results

\begin{tabular}{||c|cc|cc||}
\hline & \multicolumn{2}{|c|}{ Workday } & \multicolumn{2}{c|}{ Nonworkday } \\
& Lights & Plugs & Lights & Plugs \\
\hline \hline & & & & \\
F statistic & 36.0648 & 8.2753 & 8.7512 & 8.4915 \\
P value & $1.38 \mathrm{E}-39$ & $3.41 \mathrm{E}-11$ & $7.85 \mathrm{E}-10$ & $1.43 \mathrm{E}-09$ \\
F critical & 1.8783 & 1.8783 & 1.9388 & 1.9388 \\
& & & & \\
\hline
\end{tabular}

A complete listing of the results of the ANOVA test is included in the Appendix.

\subsection{Regression Analysis}

Because the ANOVA test indicated that the monthly means were not equal within experimental uncertainty and the plots seemed to show the values to increase with time, the next step was to construct a regression line to fit the data. The slope of the regression line is a good indicator of the amount of increase or decrease over time. The results of the regression analysis are given in Table 3.2 .

Figure 3.4 shows the workday average lighting demand each month with a regression line plotted to fit the data. The regression line has a slope of $0.3652 \pm 0.1077 \mathrm{~kW} / \mathrm{mo}$. The nonworkdays also experienced a similar increase. Figure 3.5 shows the nonworkday average lighting demand each month with a regression line plotted to fit the data. The regression line has a slope of $0.3408 \pm 0.1240 \mathrm{~kW} / \mathrm{mo}$. This is a yearly increase of $20.4 \%$.

Table 3.2. Regression Analysis Results

\begin{tabular}{||c|cc|cc|}
\hline & \multicolumn{2}{|c|}{ Workday } & \multicolumn{2}{c|}{ Nonworkday } \\
& Lights & Plugs & Lights & Plugs \\
\hline \hline \multirow{3}{*}{ slope } & & & & \\
confidence Interval & 0.3652 & 0.0912 & 0.3408 & -0.1366 \\
& 0.1077 & 0.2681 & 0.1240 & 0.3756 \\
\hline
\end{tabular}




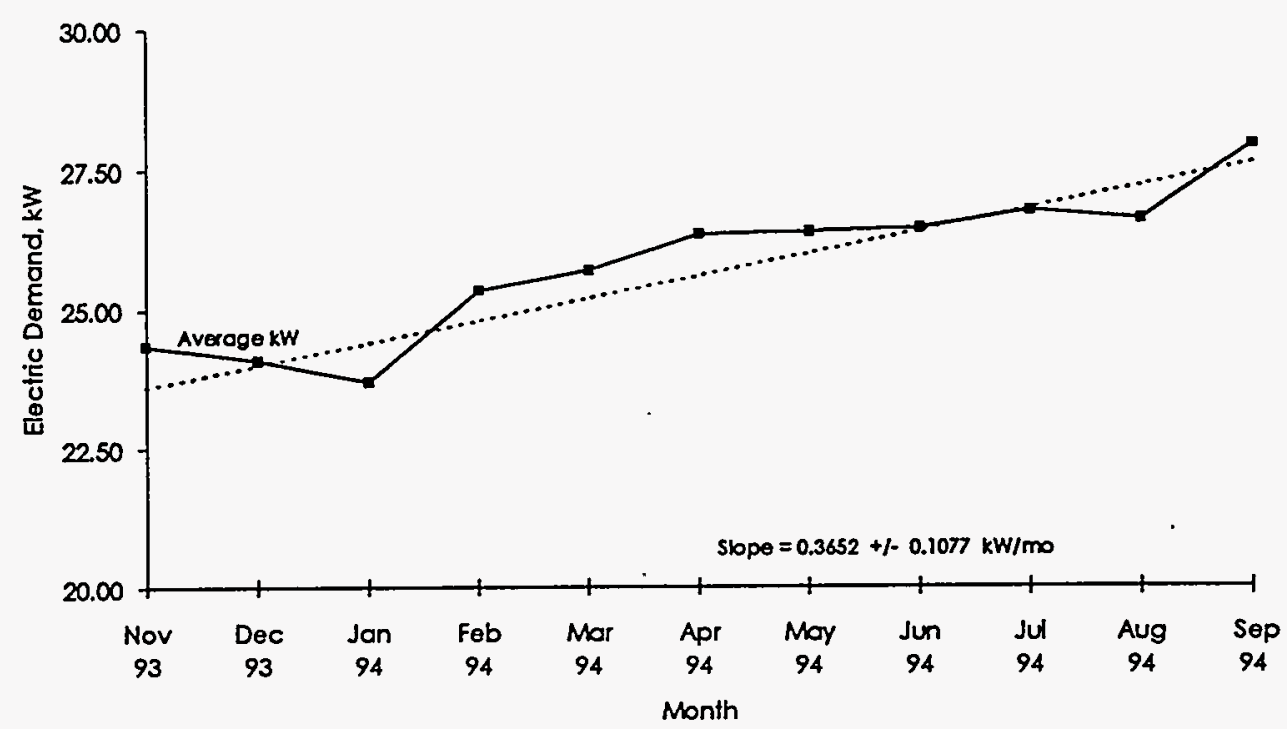

Figure 3.4. Workday Average Lighting Demand Each Month

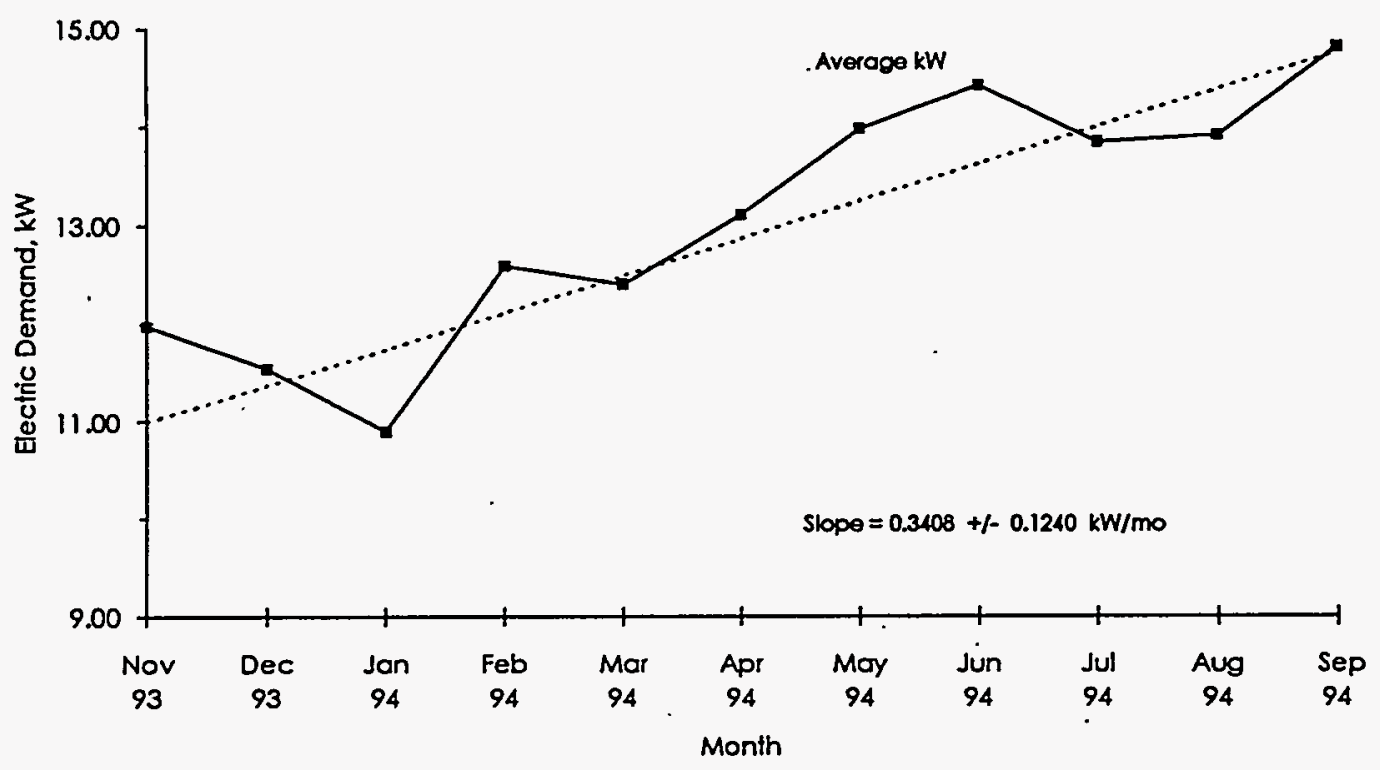

Figure 3.5. Nonworkday Average Lighting Demand Each Month 
The general upward trend is definite. The two dips in the data during December/January and July/August indicate periods when personnel are out of the building on vacation and travel. The upward surge in lighting loads in September could also be caused by the end of DOE's fiscal year. By combining the workday and nonworkday profiles, assuming 250 workdays/year and 115 nonworkdays/year, the combined monthly increase is $0.3575 \mathrm{~kW} / \mathrm{mo}$.

A particularly interesting result is that workday plug loads increased only slightly during this study period. The regression line fitting the data has a slope of $0.0912 \pm 0.2681 \mathrm{~kW} / \mathrm{mo}$ (Figure 3.6). Over 12 months, the average workday demand increased $1.094 \mathrm{~kW}$. Using a y-intercept of 27.84 amounts to a yearly increase of $3.9 \%$. This fits well with the $3.8 \%$-per-year increase experienced between Phases One and Two.

The nonworkday plug loads actually decreased during this period. The regression line fitting the nonworkday plug-load data has a slope of $-0.1366 \pm 0.3756 \mathrm{~kW} / \mathrm{mo}$ (see Appendix). It should be noted that the confidence interval for the line is large; therefore, the increase may or may not be real. A complete listing of the results of the regression analysis is also included in the Appendix.

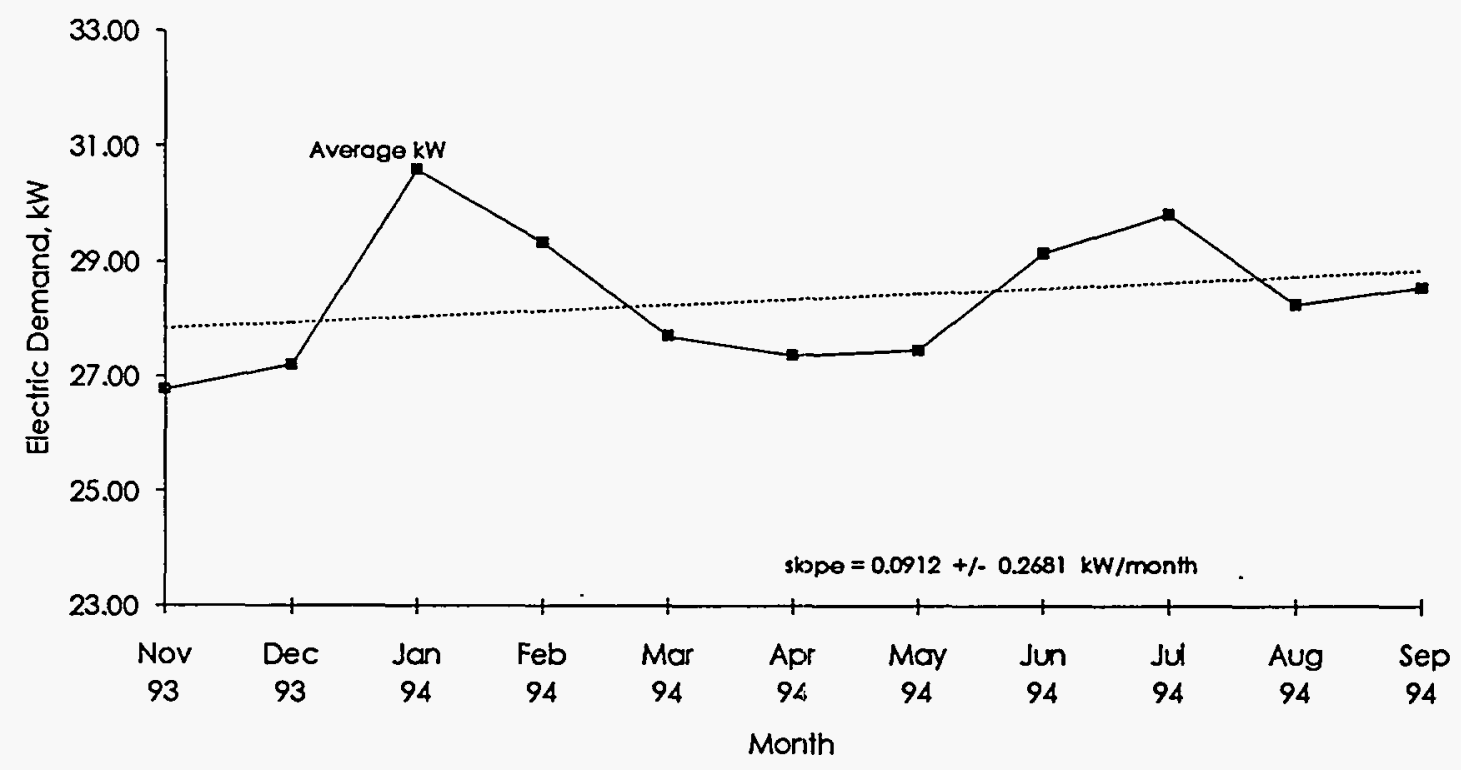

Figure 3.6. Workday Average Plug-Load Demand Each Month 


\subsection{Occupant Effects}

In any building, the behavior of the occupants can have the greatest effect on energy savings, is also the most difficult influence to measure, and can change rapidly. Although there are no data to support this assumption, it is likely that, immediately after the lighting retrofit, building occupants were on their "best behavior." The lighting retrofit was well publicized and, for several months, everyone was stepping around contractors changing lights and lighting fixtures. This served as a reminder to turn off lights to save energy. As time went by, however, the people tended to return to their old behavior.

The experience of the Canadian National Research Council helps us understand the Forrestal Building data. They found that an energy-awareness campaign to encourage people to turn off their computer monitors produced an energy savings of $14 \%$. Only 8 weeks after their energy awareness campaign was over, energy consumption had returned to its original level (Newsham and Tiller 1994).

The total energy savings determined from the Phase Two monitoring were grouped into two components: the savings from the new lighting fixtures and the savings from the increased energy awareness of the building occupants. Newsham and Tiller (1994) demonstrated that, without continual reminders, the energy awareness component will eventually return to zero, leaving savings from only the fixture replacement. 


\subsection{Conclusions}

The third phase of the energy-use monitoring study of the Forrestal Building revealed that, though an initial savings was realized, the electric demand has been steadily climbing since the end of the retrofit in September 1993 (Figure 4.1). The increase is attributed to occupants returning to pre-retrofit behavior and the possibility of occupancy sensors being defeated.

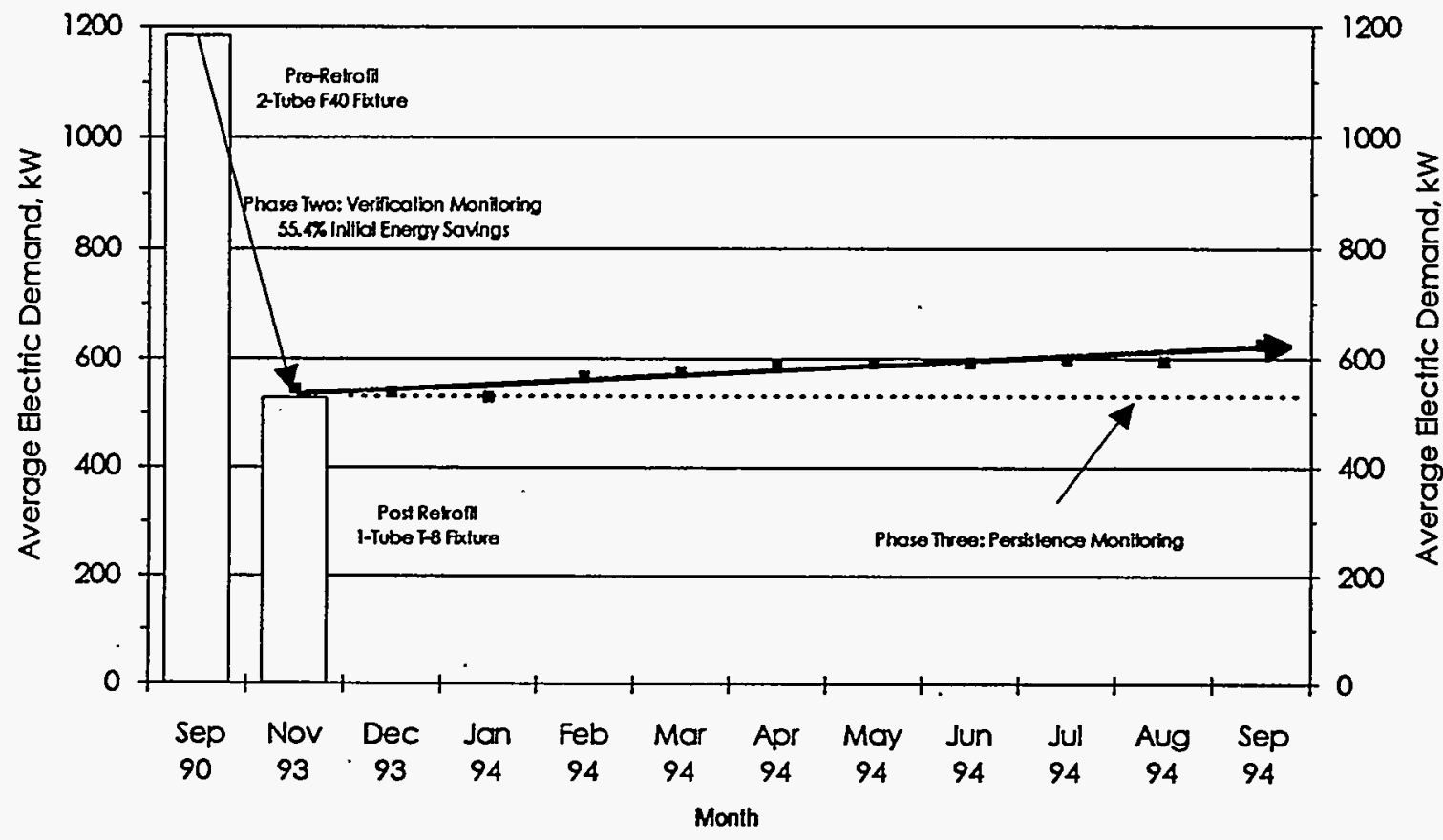

Figure 4.1. Energy-Use Summary

The increase is not expected to continue indefinitely, but should level off at some value below the pre-retrofit demand. The difference between the pre-retrofit demand and the demand at the end of Phase Three monitoring is the true energy savings - quite different from the initial energy-savings figure.

The project in the Forrestal building was well publicized, increasing the amount of occupant behavior changes. Newsham and Tiller (1994) showed that, over time, the occupant effects lessen and true savings can be assessed. The length of time it takes for occupant effects to wear off 
varies by building. Data were collected for 11 months at the Forrestal Building and the asymptotic "leveling off value" cannot yet be determined.

The data loggers currently installed in the Forrestal Building will be left in place to track the increase in electric demand over time and to identify when the demand begins to level out. Until the demand levels out, an accurate assessment of the actual savings of the lighting retrofit cannot be made. 


\subsection{References}

Halverson, M. A., J. L. Stoops, J. R. Schmelzer, W. D. Chvála, J. M. Keller, and L. Harris. 1994. "Lighting Retrofit Monitoring for the Federal Sector - Strategies and Results at the DOE Forrestal Building." In Proceedings of the American Council for an Energy Efficient Economy 1994 Summer Study on Energy Efficiency in Buildings, Vol. 2, pp. 2.137-2.144, August 28 September 3, 1994, Pacific Grove, California. ACEEE, Washington, D.C.

Mazzucchi, R. P. 1992. "End-Use Profile Development from Whole-Building Data Combined with Intensive Short-Term Monitoring." ASHRAE Transactions 98(1): 1180-1184.

Newsham, G. R., and D. K. Tiller. 1994. "The Energy Consumption of Desktop Computers: Measurement and Savings Potential." IEEE Transactions on Industry Applications 30(4).

Stoops, J. L., J. R. Schmelzer, R. Smith, and R. P. Mazzucchi. 1990. "Forrestal Building Electrical Consumption." In Attachment 8 to Shared Energy Savings (SES) Lighting Retrofit Project on the Forrestal Building, Washington, D.C. U.S. Department of Energy Solicitation Number DE-RP01-91MA69008, prepared by Pacific Northwest Laboratory for the U.S.

Department of Energy, Washington, D.C. 
Appendix 


\section{Appendix}

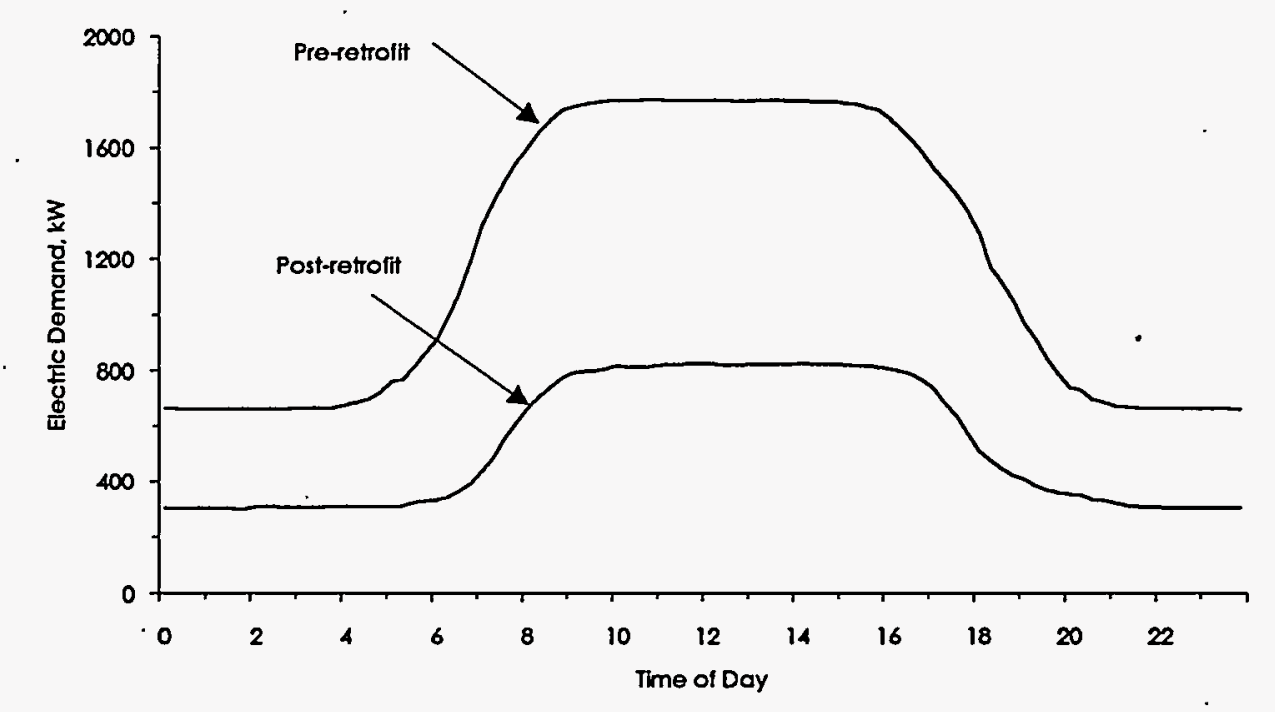

Figure A.1. Workday Lighting-Demand Profile

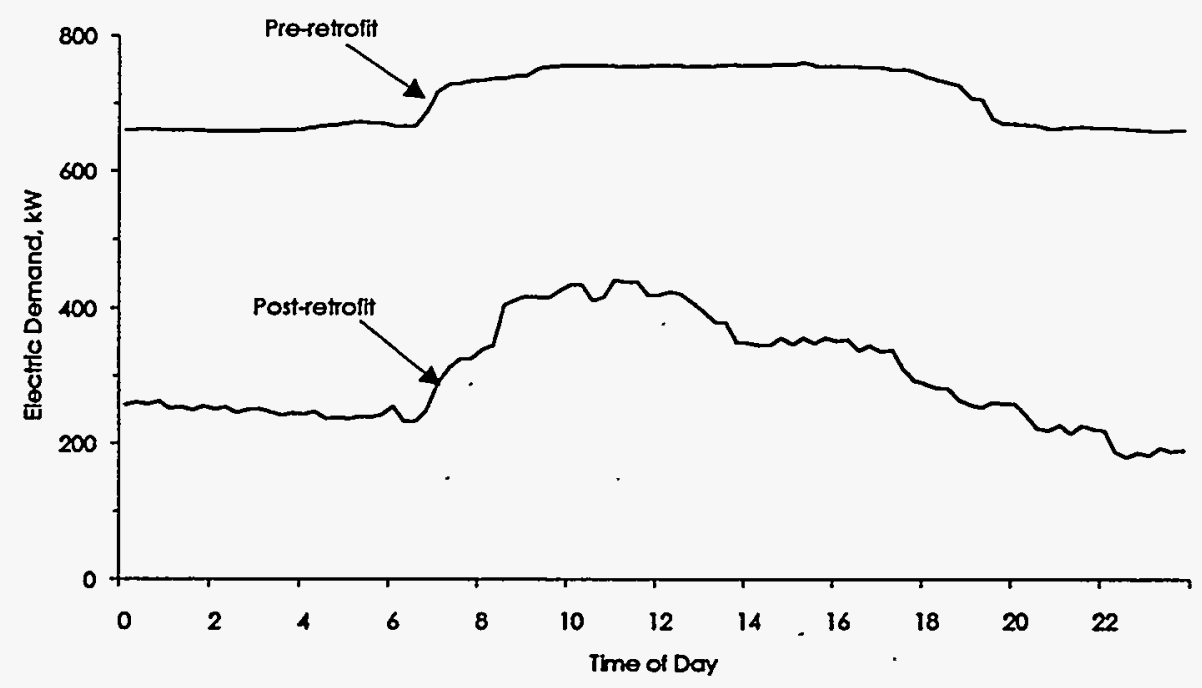

Figure A.2. Nonworkday Lighting-Demand Profile

A.1 


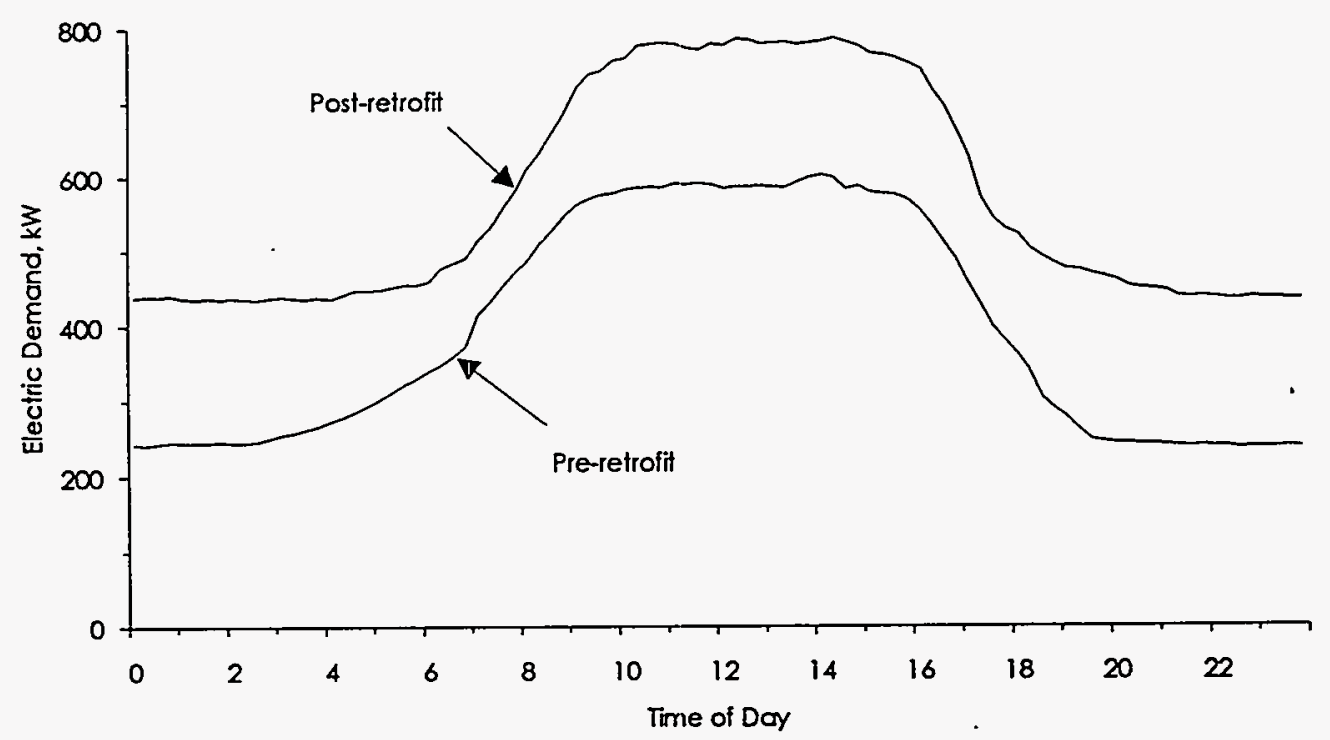

Figure A.3. Workday Plug-Load-Demand Profile

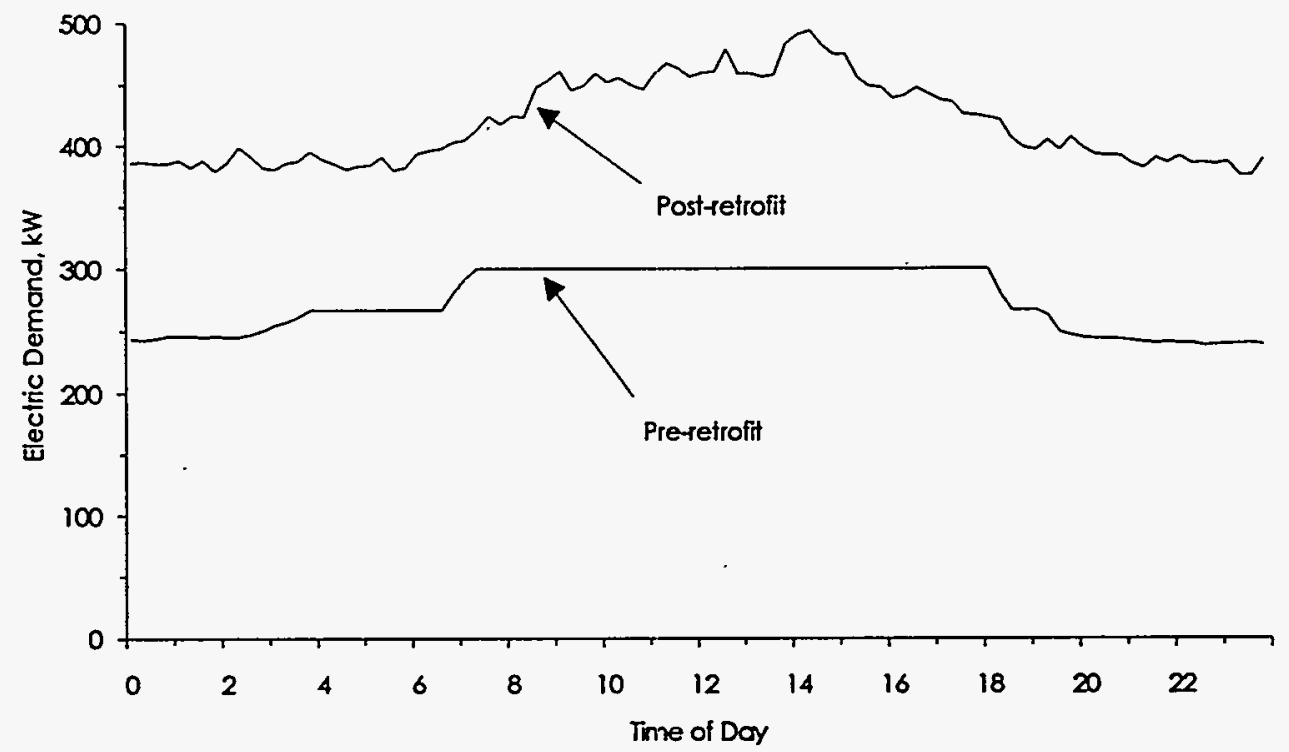

Figure A.4. Nonworkday Plug-Load-Demand Profile 


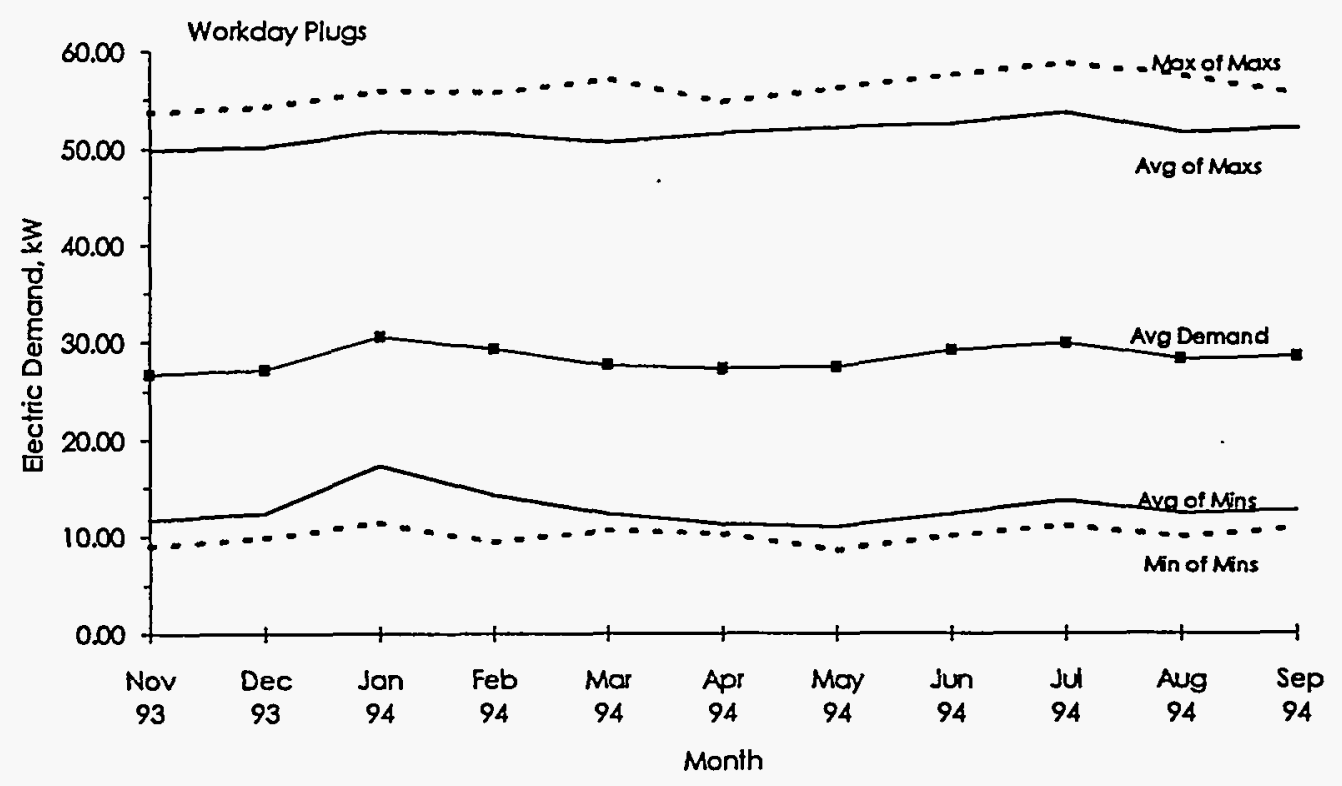

Figure A.5. Workday Plug-Load Monthly Statistics

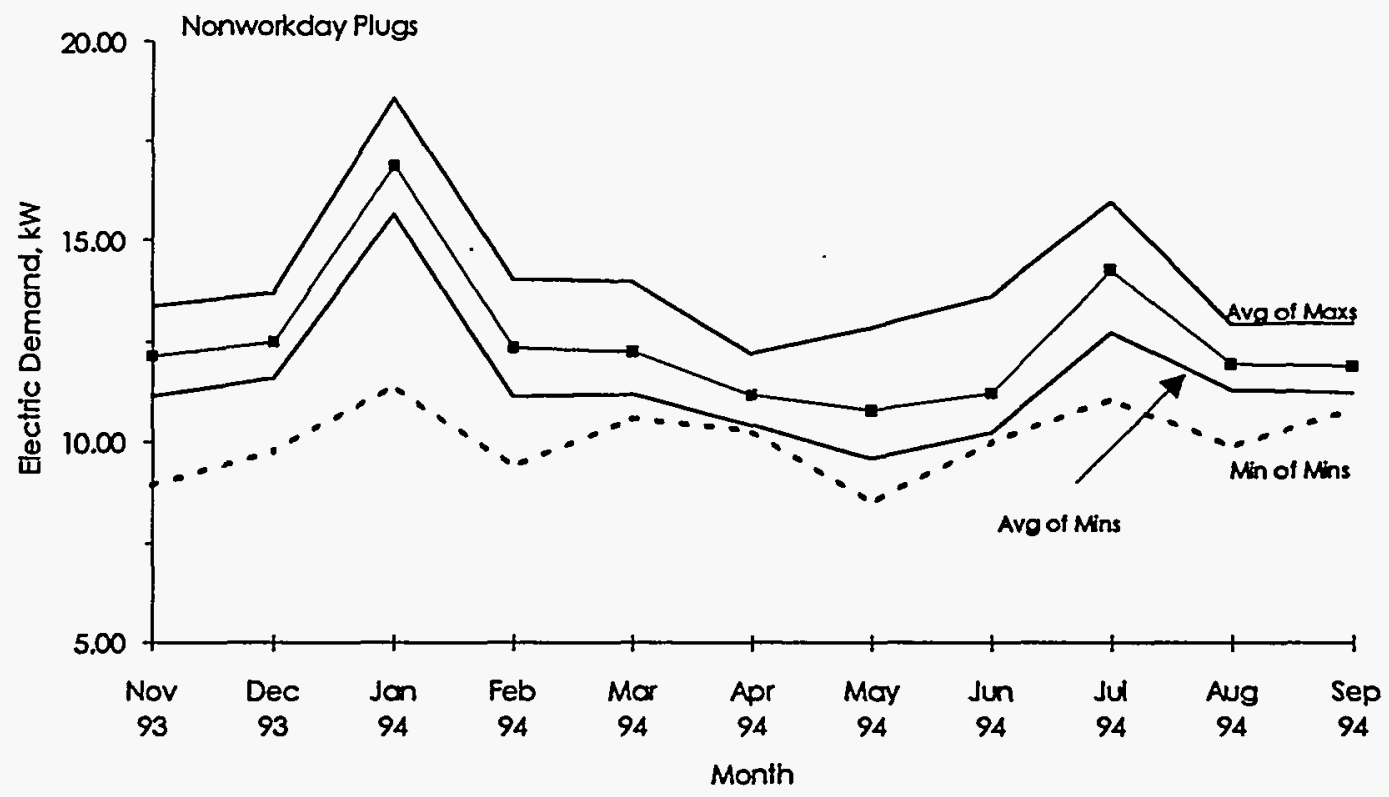

Figure A.6. Nonworkday Plug-Load Monthly Statistics 


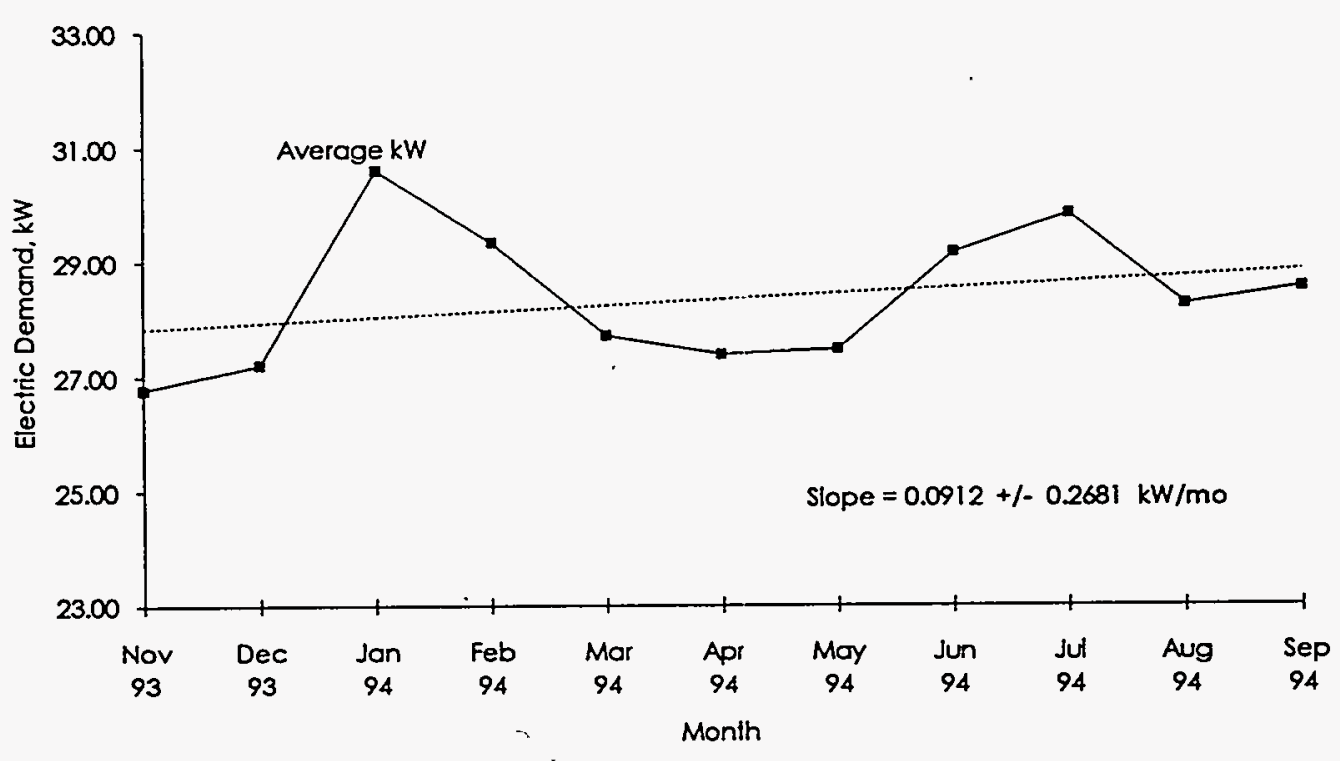

Figure A.7. Workday Average Plug-Load Demand Each Month

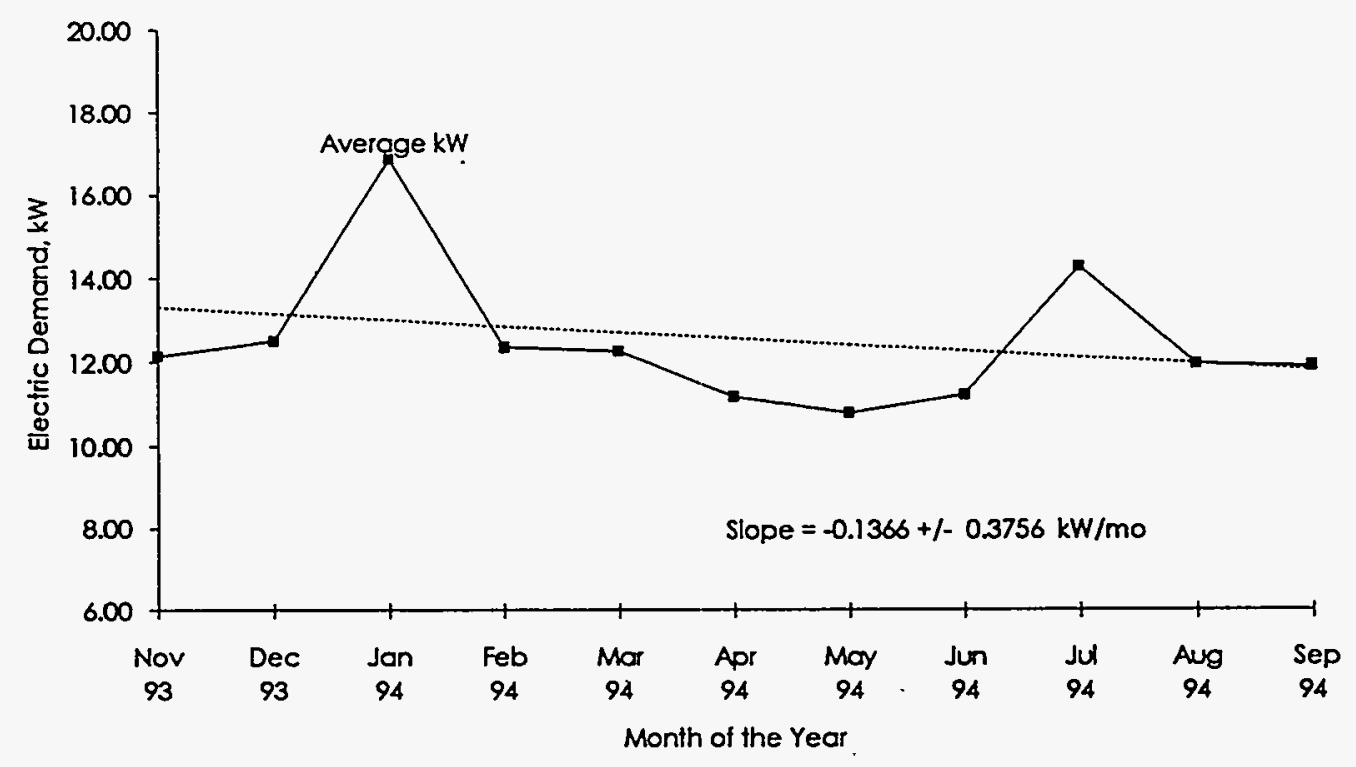

Figure A.8. Nonworkday Average Plug-Load Demand Each Month 


\section{Distribution}

No. of

Copies

Offsite

2 DOE/Office of Scientific and Technical Information

M. Ginsberg

Federal Energy Management Program U.S. Department of Energy, CE-44 1000 Independence Avenue SW

Washington, DC 20585

2 L. R. Harris

Federal Energy Management Program U.S. Department of Energy, CE-44 1000 Independence Avenue SW Washington, DC 20585

K. D. DeVine

Federal Energy Management Program U.S. Department of Energy, CE-10.1 1000 Independence Avenue SW Washington, DC 20585

V. Petrolatti

DOE/In-House Energy Management

U.S. Department of Energy

1000 Independence Avenue SW

Washington, DC 20585

E. J. Vajda

Building Manager

Forrestal Building

U.S. Department of Energy

1000 Independence Avenue SW

Washington, DC 20585
No. of

Copies

Offsite

M. Schincovich

U.S. Department of Energy

1000 Independence Avenue SW

Washington, DC 20585

J. S. Haberl

Energy Systems Laboratory

Department of Mechanical Engineering

Texas Engineering Experiment Station

Texas A\&M University

College Station, TX 77843-3123

Onsite

DOE Richland Operations Office

J. K. Schmitz

K8-50

$30 \quad$ Pacific Northwest Laboratory

P. R. Armstrong

K5-08

W. D. Chvála, Jr. (5)

K5-08

L. K. Fastabend (2)

K5-06

M. A. Halverson (5)

K5-08

W. D. M. Hunt

BWO

B. A. Mohler

K5-02

G. B. Parker

K9-62

D. R. Payson

K7-90

C. W. Purcell

BWO

W. F. Sandusky III

K5-08

J. R. Schmelzer

K5-08

D. W. Schrock

K5-16

J. L. Stoops

K5-08

E. E. Richman

K5-08

R. R. Wahlstrom (2)

K5-08

Technical Report Files (5)

Distr.1 